\title{
Blood parasite biodiversity of reef-associated fishes of the eastern Caribbean
}

\author{
Courtney A. Cook ${ }^{1}$, Paul C. Sikkel ${ }^{1,2}$, Lance P. Renoux ${ }^{2}$, Nico J. Smit ${ }^{1, *}$ \\ ${ }^{1}$ Water Research Group, Unit for Environmental Sciences and Management, North-West University, Potchefstroom 2520, \\ South Africa \\ ${ }^{2}$ Department of Biological Sciences and Environmental Sciences Program, Arkansas State University, State University, \\ Arkansas 72467, USA
}

ABSTRACT: Parasitic micro-organisms can influence multiple ecological processes, from growth, mortality, and behavior, to community structure and trophic interactions, yet are typically ignored components of marine biodiversity. We collected 1298 blood samples from reef fishes off 6 eastern Caribbean islands, representing 27 families, 57 genera and 103 species, including invasive Indo-Pacific lionfish. Members of 14 species from 8 families were infected, comprising damselfishes (Pomacentridae), parrotfishes (Scaridae), mullet (Mugilidae), jacks (Caranjidae), Blennies (Blenneidae and Labrisomidae), snappers (Lutjanidae), and angelfishes (Pomacanthidae). None of the 8 distinct blood parasites found fit descriptions of other Caribbean parasites, but resembled typical Haemogregarina-like intraerythrocytic parasites and Haemohormidium-like parasites collected from fishes on the Great Barrier Reef (GBR), Australia. No blood parasites were found in lionfish and there was surprisingly little overlap in the families of Caribbean and GBR fishes. Most infected species were strongly diurnal. The high incidence of infection in Stegastes damselfishes was particularly surprising and has potentially important ecological consequences, given that damselfishes influence benthic community structure and are prey for reef piscivores. Gnathiid isopods, an apparent vector of apicomplexan blood parasites in other systems, were common at sampling sites and collected for use in transmission experiments. Haemogregarinalike parasites were taken up by gnathiids that fed on infected blennies. By comparison, when gnathiids fed on Stegastes damselfish infected with a Haemohormidium-like parasite, no parasites were found. This study reveals the high biodiversity of haemoparasites infecting eastern Caribbean reef fishes, and highlights the need for additional research throughout the Caribbean and in other tropical reef systems.

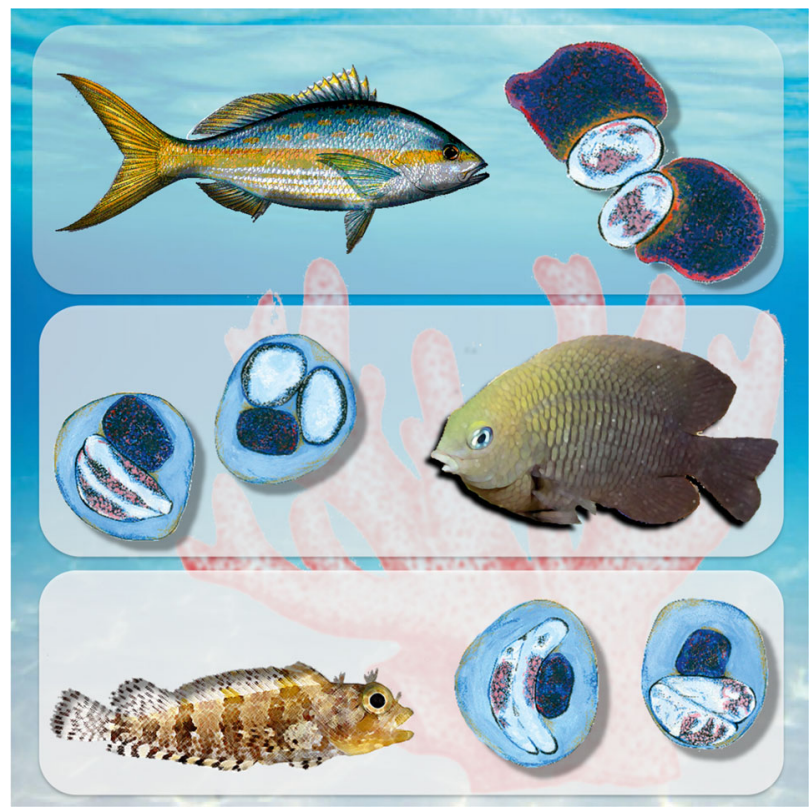

Survey of eastern Caribbean reef-associated fishes shows a high biodiversity of unique blood parasites

Image: Courtney A. Cook, Edward C. Netherlands

KEY WORDS: Coral reefs · Marine reserves · Recovery rates - Spatial comparisons - Temporal monitoring · Philippines

Resale or republication not permitted without written consent of the publisher

\section{INTRODUCTION}

The major challenge facing ecologists, conservationists, and managers of marine reef ecosystems is to understand the complex biological interactions 
that occur within and between reef-associated habitats and how these interactions are affected by anthropogenic activity. Research on the biological diversity and complexity of marine ecosystems has historically focused on macrofauna that are easily seen and surveyed by scientists. Thus, the understanding of the diversity and function of microorgansims constitutes a current frontier in research on marine biocomplexity (e.g. Das et al. 2006). Many of these organisms function as parasites. Indeed, parasitism is the most common animal lifestyle and thus the most common biological interaction (Hudson et al. 2006). Because of their effects on host population dynamics, parasites directly or indirectly influence biodiversity of ecological communities in general (e.g. Wood et al. 2007, Hatcher \& Dunn 2011).

While recent studies of marine parasites have made substantial contributions to our understanding of the role of parasites in ecosystems generally (Huxham et al. 1995, Thomas et al. 1998, Mouritsen \& Poulin 2005, Thompson et al. 2005, Arias-González \& Morand 2006, Lafferty et al. 2006, Kuris et al. 2008, Dunne et al. 2013), our understanding of the diversity and role of parasites in marine systems has been driven primarily by studies of easily accessible, 'model' systems, commercially important species, and opportunistic observations (reviewed by Poulin et al. 2014). Given that the discovery of marine parasite species over time continues to accelerate (rather than asymptote), simply characterizing the parasite fauna in marine systems constitutes a major challenge to understanding their role in marine communities (Poulin et al. 2014).

Because of their ease of access, working conditions that facilitate extended time in the field, and their high biodiversity, coral reefs are one of the most intensively studied marine ecosystems. However, parasites may comprise as much as $80 \%$ of the organisms on tropical reefs (Rohde 2002), and few coral reef ecologists are trained in parasitology. Initial efforts to characterize blood parasites in coral reef fishes were conducted in the 1950s and 1960s by Laird (1951) working in Fiji, and by Saunders (1954, 1955, 1958a,b, 1959a,b, 1960, 1964, 1966) working in the Caribbean and Red Sea. Based on the widespread occurrence of haemogregarine apicomplexans in terrestrial vertebrates, these studies focused on haemogregarines. Subsequent studies were not conducted until over 20 yr later (Burreson 1989), and then again not until after the turn of the century (Smit et al. 2006, Curtis et al. 2013), all focused on the Great Barrier Reef (GBR).
Laird (1951) described Haemogregarina salariasi from his survey of 193 fishes of 22 species from the reefs off Fiji, however this species was later synonomised with $H$. bigemina (see Siddall 1995). Saunders $(1954,1955,1958 b, 1964)$ reported, from her combined sample of 2640 fishes from 57 species and 23 families from the Caribbean region, one unnamed haemogregarine, along with Haemogregarina achiri, $H$. dasyatis and $H$. brevoortiae (Saunders 1964). Saunders (1960) also described $H$. rubrimarensis from the Red Sea samples of 1541 fishes from 104 species. Along with these descriptions, Saunders (1954, 1955, 1958a,b, 1959a, 1960, 1964, 1966) reported H. bigemina from all collection localities - a haemogregarine now thought to be of questionable cosmopolitan distribution (see Davies et al. 2004). Similarly, from the GBR, Burreson (1989) reported 3 species of Haemogregarina in a survey including 69 fishes belonging to 28 species from Heron Island, and Smit et al. (2006) documented 4 haemogregarines during a survey involving 497 fishes from 78 species from Lizard Island. In both surveys of the GBR above, nonhaemogregarine blood parasites were reported along with observations of $H$. bigemina or $H$. bigemina-like haemogregarines. These included 2 species of Trypanosoma and 1 species of Haemohormidium from fishes off Heron Island (Burreson 1989), as well as a Haemohormidium-like infection from fishes off Lizard Island (Smit et al. 2006). Astonishingly, with all the surveys carried out by Saunders (1954, 1955, 1958a,b, 1959a,b, 1966), non-haemogregarine blood parasites such as those above collected from other coral reef environments were not identified, discovered, or described from reef-associated fishes of the Caribbean, except for a single record where Saunders (1959b) described a trypanosome, Trypanosoma balistes Saunders, 1959, from Balistes capriscus (Balistidae). This is particularly interesting since Saunders (1960) did describe other non-haemogregarine infections from fishes of the Red Sea including a species of Babesiosoma and Dactylosoma. While Saunders' efforts were impressive, her studies focused on species commonly caught in local fisheries, including some pelagic species. In addition, her studies, as with those of Laird (1951), were conducted using inferior (by modern standards) microscopy, and included neither photographic evidence nor voucher specimens.

While little is known about blood parasites of coral reef fishes, even less is known about how they are transmitted (Smit et al. 2006), with few attempts at vector identification and experimental transmission (Smit et al. 2006, Curtis et al. 2013). Furthermore, 
since haemogregarines are the most commonly recorded blood parasites of coral reef fishes, the focus of transmission studies has been on these parasites. Leeches were for a long period assumed to be the main vectors of these fish blood parasites, particularly of haemogregarines (Davies \& Smit 2001, Smit et al. 2006). However, Davies \& Johnston (1976) and Davies $(1982,1995)$ proposed that gnathiid larvae (Isopoda: Gnathiidae) may be vectors of the cosmopolitan $H$. bigemina. This suggestion was later supported by observations made by Davies et al. (1994), Smit \& Davies (1999), Davies \& Johnston (2000) and Smit \& Davies (2001). Generally, however, gnathiid isopod larvae have been implicated along with leeches in the transmission of haemogregarines in both cold and temperate regions (Davies \& Smit 2001, Hayes et al. 2006), whilst for more tropical warmer regions, such as the GBR, only gnathiids have been associated with haemogregarine transmission (Smit et al. 2006, Curtis et al. 2013). Such a finding may be attributable to the apparent low abundance of leeches in tropical waters (Smit et al. 2006). Furthermore, Smit et al. (2006) suggested that the larvae of gnathiids, particularly since they are such an abundant parasitic isopod of coral reef fishes, may be responsible for the transmission of not only the haemogregarine parasites, but possibly some of the non-haemogregarine blood parasites as well.

The aim of the present project was thus to first establish the biodiversity of blood parasites from the fishes of the eastern Caribbean, as the current knowledge based on the work of Saunders (1954, 1955, 1958a,b, 1959a,b, 1966), who reported only 5 blood parasites, comprising only 1 trypanosome and 4 haemogregarines, does not reflect the high parasite diversity expected to be associated with coral reef ecosystems (Adlard et al. 2015). Secondly, the present study aimed to determine the presence of possible vectors of these blood parasites, and to test their transmission potential.

\section{MATERIALS AND METHODS}

\section{Fishes}

The focus of the fish collection for the present study was on adult and sub-adult specimens from reefassociated species common at each of the study sites (see below) as well as less common species from families that have been shown to be infected with blood parasites in other parts of the world and/or which were included in Saunders' previous studies in the
Caribbean region (Saunders 1955, 1958a,b, 1959a,b, $1964,1966)$. Fish were collected over a period of 11 mo (June 2012 up to and including April 2013) by divers using hand nets and modified cast nets as described in Sikkel et al. (2009a), or obtained from local fishermen. Collection sites included (from east to west) St. Maarten $\left(18.06^{\circ} \mathrm{N}, 63.05^{\circ} \mathrm{W}\right)$, Saba $\left(17.63^{\circ} \mathrm{N}, 63.23^{\circ} \mathrm{W}\right)$, Guana Island, British Virgin Islands $\left(18.50^{\circ} \mathrm{N}, 64.63^{\circ} \mathrm{W}\right)$, St. John, US Virgin Islands $\left(18.33^{\circ} \mathrm{N}, 64.73^{\circ} \mathrm{W}\right)$, St. Thomas, US Virgin Islands $\left(18.33^{\circ} \mathrm{N}, 64.91^{\circ} \mathrm{W}\right)$, and Culebra, Puerto Rico $\left(18.31^{\circ} \mathrm{N}, 65.29^{\circ} \mathrm{W}\right)$. These sites were chosen based on the availability of fish and the presence of facilities to support holding and sampling of fish.

Immediately after collection, fish were placed in plastic holding tanks with fresh, aerated seawater until sampling. All blood samples were taken within $24 \mathrm{~h}$ of capture. Fish collected by divers were anesthetized in a bath of seawater containing clove oil solution prior to sampling (Smit et al. 2006) and returned to the place of capture during the daylight hours on the day following capture. Fish obtained from fishermen were anesthetized by chilling and humanely sacrificed after sampling and returned to the fishermen for market. All fish were measured prior to sampling (standard, fork, and total length). Fish were also visually inspected for any ectoparasites that have previously been shown to act as potential vectors of blood parasites; these include specifically leeches (Hayes et al. 2006, Hayes et al. 2014) and gnathiid isopods (Davies \& Smit 2001, Curtis et al. 2013).

The total number of fishes screened for blood parasites included 1298 individuals from 27 families, 57 genera and 103 species. The most fishes were screened from St. Thomas (522 fishes), followed by St. John (313), Culebra (251), Saba (87), Guana (85) and St. Maarten (40). These included native Caribbean species, as well as invasive Indo-Pacific lionfish (the full list is given in Table S1 in the Supplement at www.int-res.com/articles/suppl/m533p001_supp.pdf).

\section{Blood parasites}

Blood was drawn from the caudal artery via syringe with a 26 to 30 gauge needle, depending on fish size, and 3 replicate blood smears were made for each fish, using a single drop of blood placed on each of 3 glass slides. Blood smears were allowed to dry for 5 to 10 min before fixing with absolute methanol in a dustproof container. One smear from each fish was later stained with a modified solution of Giemsa stain 
(FLUKA, Sigma-Aldrich) and examined under oil immersion at $100 \times$ magnification using a Nikon Eclipse 80i compound microscope (Nikon) (Smit \& Davies 1999). Photographs of blood parasites were taken with the attached Nikon DS-Fi1 camera and measurements of the peripheral blood parasite stages were determined with the aid of allied Nikon NISElements microscope imaging software program D3.2 (Nikon). Parasitaemia (the level of infection) was calculated per 100 erythrocytes, following the method of Cook et al. (2009), but with $10^{8}$ erythrocytes examined per blood smear owing to such a low incidence of infection in this study. Low parasitaemia $<1$ to $40 \%$ ) was described as a chronic infection, whilst high parasitaemia ( $>40$ to over $80 \%$ ) was described as an acute infection.

\section{Experiments with gnathiid isopod larvae}

Gnathiids were collected for the establishment of breeding colonies, using techniques outlined by Sikkel et al. (2006, 2009b). Briefly, fish were deployed in plastic cages on the reef between 17:00 h and 05:30 h corresponding with the peak in gnathiid activity (Sikkel et al. 2006). Fish species (Epinephelus guttatus, Haemulon flavolineatum, Haemulon sciurus) that were negative for blood parasites were used for gnathiid collection. Gnathiids were allowed to finish feeding and were then transferred to specimen jars and allowed to molt, usually taking between 5 and $7 \mathrm{~d}$. Once molted, males and females were isolated into breeding colonies with a ratio of 1 or 2 males to 8 or 9 females. Small pieces of waterproof paper were added to the container to provide shelter. Once the larval gnathiids were visible in the brood pouch, the gnathiid females were transferred carefully to isolation and the larvae were allowed to hatch. Zuphea were allowed to fast for 24 to $48 \mathrm{~h}$ to ensure that the yolk was fully absorbed. Once this fasting period was complete, zuphea were mixed with other zuphea from other females to reduce bias.

To maximize the likelihood of gnathiid feeding, feedings were conducted in small plastic containers (or plastic buckets if fish size was too large) half-filled with water, along with a plastic mesh and small rocks for gnathiid cover. Aerators were used to provide oxygen and adjusted to a low speed to avoid damaging the gnathiids. Fish species used included the dusky damselfish Stegastes adustus, threespot damselfish Stegastes planifrons, redlip blenny Ophioblennius macclurei, palehead blenny Labrisomus gobio and the French grunt Haemulon flavolineatum.
French grunts were used as control because we never found them to harbor blood parasites ( $\mathrm{n}=75)$. Fish were then transferred from holding aquaria to feeding containers and allowed to acclimate before introduction of gnathiids. Gnathiids were slowly poured into the container, with care taken to add all zuphea from containers.

Once gnathiids were added, fish were observed until gnathiids attached. A piece of cloth mesh was placed over the container to prevent fish escape and a box was placed over the containers to minimize light exposure. Gnathiids were allowed to feed for $\sim 12 \mathrm{~h}$ to ensure all gnathiids had sufficient time to complete feeding. Once the 12 -h period was complete, the fish was inspected and washed with seawater from a squirt bottle to dislodge any gnathiids still attached. Fish were then placed in recovery buckets with Stresscoat (API) and transferred to the holding tanks. To reduce stress on individual fish, a rest period of 48 to $72 \mathrm{~h}$ was used between vector transmission trials. Gnathiids used in vector experiments were recovered by filtering the contents of the container through plankton mesh and transferred to specimen containers. A sub-sample of fed gnathiids was then serially squashed on glass slides each day until 2 or 3 days post-molt.

\section{RESULTS}

\section{Blood parasites}

In addition to providing the most comprehensive modern survey of blood parasites of coral reef fishes, we aim to make the material easily accessible to nonspecialists. We therefore present 'Remarks' that normally appear in 'Results' sections of parasitological journals in the Supplement (www.int-res.com/articles/ suppl/m533p001_supp.pdf).

Five types of blood parasites, all intraerythrocytic except 2 (see below), were observed parasitising the fish examined during this study, Haemohormidiumlike infections being the most common, followed by viral-like inclusions, as well as less commonly encountered parasites such as haemogregarines and Babesiosoma-like parasites. The fifth type of parasite is of unknown identity, and its morphology did not provide any indication of its possible generic placement. No trypanosomes were observed.

Of the 1298 fish screened, 123 (9\%) had blood parasites. The highest prevalence (38\%) was observed in the fishes collected off St. Maarten, most of which were Stegastes damselfishes infected with a Haemo- 
hormidium-like infection. Similar infections, ranging from a chronic to an acute infection (on average 1 to $40 \%$ of erythrocytes infected, respectively), were also observed in fishes collected off the other 5 islands, this parasite thus presenting with a wide distribution as well as host record, infecting 6 different species (Table S1 in the Supplement).

\section{Descriptions of the blood infections}

As mentioned previously, the intraerythrocytic and intraleucocytic infections observed in the blood films from the fishes studied may constitute as many as 10 morphologically different species, but it is difficult to be certain in all cases. These parasites include at least 3 different Haemohormidium-like infections, 5 different haemogregarine infections, one viral infection and one infection of unknown identity. Dimensions are given as mean \pm SD (range).

\section{Haemohormidium-like infections}

Four species of Stegastes (Pomacentridae) and 2 species from the genera Scarus and Nicholsina (Scaridae) were infected with what appeared to be a similar type of Haemohormidium-like infection. Stages observed included possible early to late stage trophozoites measuring $3.9 \pm 0.4(3.6-4.3) \times 1.7 \pm 0.4$ $(1.3-2.2) \mu \mathrm{m}(\mathrm{n}=3)$ with whitish foamy cytoplasm and pale purple loose chromatin (Fig. 1a,b); as well as slender dividing stages, with whitish cytoplasm, measuring $5.7 \pm 0.6(5.1-7.1) \times 1.5 \pm 0.3(1-2) \mu \mathrm{m}(\mathrm{n}=$ 10), in which up to 3 adjacent strip-like nuclei could sometimes be seen, staining pink-purple (Fig. 1c,d); the latter being the most prevalent stage. In one instance these dividing stages were observed to have separated into 3 possible 'gamont' or 'merozoite' stages measuring $4.4 \pm 0.4(4-4.8) \times 0.9 \pm 0.3(0.6-1.1) \mu \mathrm{m}$ $(\mathrm{n}=3)$ (Fig. 1e).

Another, likely different, Haemohormidium-like parasite was detected at a low intensity $(<1 \%)$ in an individual of Selar crumenophthalmus (Carangidae) collected off St. Thomas. This parasite was bean shaped (Fig. 1f) to round (Fig. 1g), measuring $3.4 \pm$ $0.4(3-3.8) \times 2.7 \pm 0.5(1.9-3.1) \mu \mathrm{m}(\mathrm{n}=4)$, with 2 small adjacent, pink-staining nuclei situated randomly in the whitish-staining cytoplasm.

A third Haemohormidium-like species was observed at a low intensity $(<1 \%)$ in a single Mugil curema (Mugilidae) from St. Thomas and a single Stegastes adustus (Pomacentridae) from Saba. Para- sites were $2.8 \pm 0.2(2.6-3.1) \times 1.7 \pm 0.5(1.3-2.3) \mu \mathrm{m}$ $(\mathrm{n}=4)($ Fig. $1 \mathrm{~h}, \mathrm{i})$. None of the above Haemohormidium-like parasites were observed parasitising leucocytes.

Intraerythrocytic cytoplasmic viral-like infections

Intraerythrocytic cytoplasmic viral-like inclusions were observed in 8 species of fish from 7 families, collected off 4 of the 6 islands comprising Culebra, Guana, St. John and St. Thomas. Such infections presented as acute (or high intensity infections, in which $80 \%$ or more of the erythrocytes were infected) in 5 of the 7 families comprising the Acanthuridae, Balistidae, Haemulidae, Lutjanidae and Serranidae; those with chronic infections (<40\% erythrocytes infected) comprised the Holocentridae and Labridae (Table S1 in the Supplement). All of these infections resembled those organisms sometimes referred to as 'bullet-hole virus', but one particular viral-like organism detected in this study was found to reside in the nucleus of the infected erythrocyte (Fig. 1j) of $2 \mathrm{H}$. flavolineatum (Haemulidae). The viral-like organism was $2 \pm 0.2$ $(1.9-2.2) \times 1.3 \pm 0.05(1.3-1.4) \mu \mathrm{m}(\mathrm{n}=3)$. None of the above were observed infecting leucocytes.

\section{Haemogregarina-like infections}

Haemogregarines were rarely observed parasitising fish during this study, parasitaemias being additionally very low $(<1 \%)$. However, possible merozoite and gamont stages resembling those of haemogregarines were seen in 5 species: Hypleurochilus bermudensis (Blenniidae) from St. Thomas; Lactophrys bicaudalis (Ostraciidae) and Pomacanthus arcuatus (Pomacanthidae) from Culebra; Nicholsina usta usta (Scaridae) from St. Thomas; and Sparisoma viride (Scaridae) from St. John (Table S1 in the Supplement). The first of these species was infected with a haemogregarine species similar to Haemogregarina bigemina Laveran and Mesnil, 1901, the latter 4 however, could not be compared any further owing to the extremely low level of parasitaemia (1-2 parasites per $10^{8}$ erythrocytes). Possible meront stages of the haemogregarine resembling $H$. bigemina, in that the meront nucleus appeared to be undergoing longitudinal binary fission, were observed intraerythrocytically, measuring $7 \pm 0.6(6.6-7.4) \times 2.9 \pm 0.2(2.7-3) \mu \mathrm{m}$ $(\mathrm{n}=2)$ (Fig. 1k). Additional stages of what was determined to be an $H$. bigemina-like parasite were detected in a single Labrisomus gobio and 9 O. mac- 


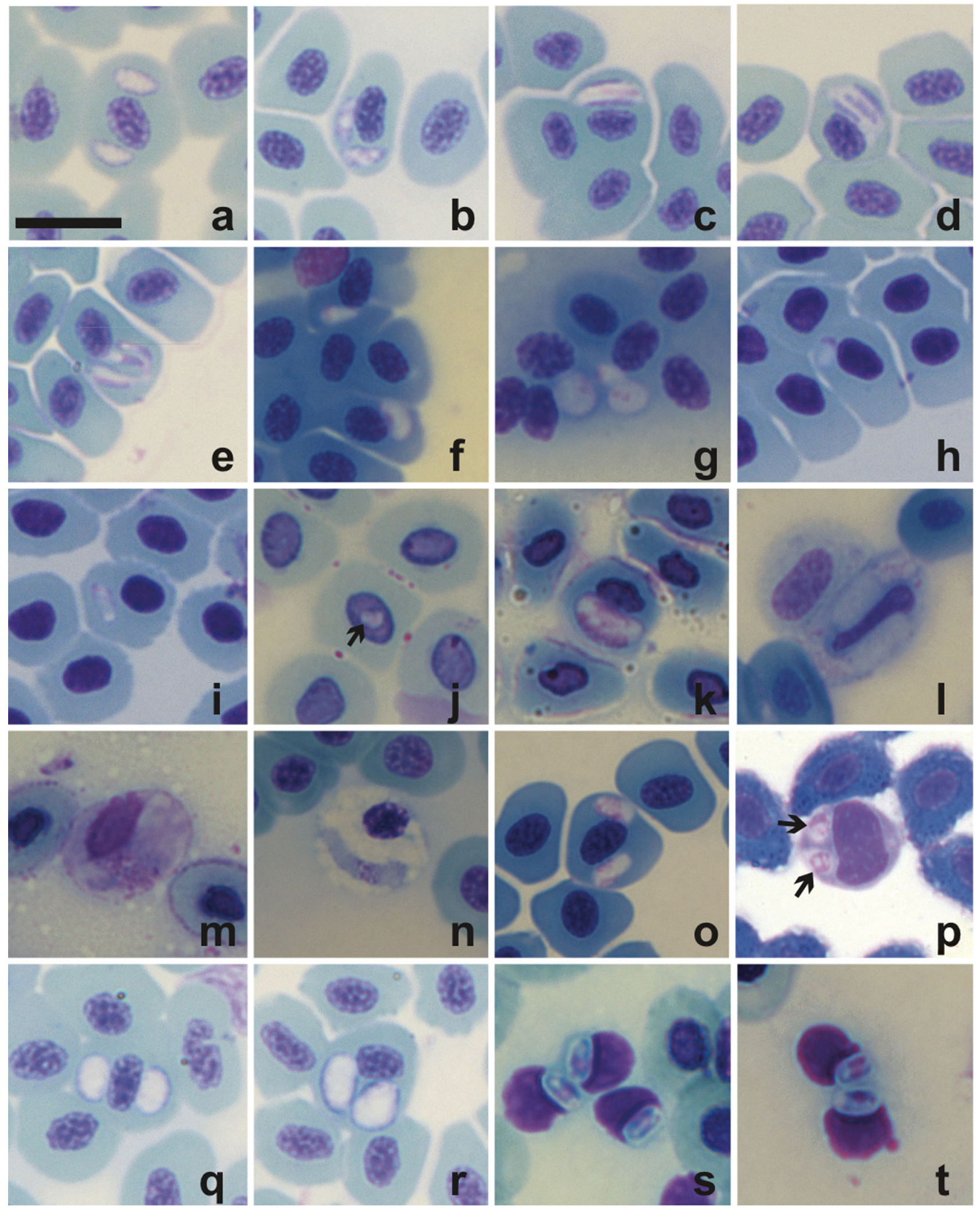


clurei captured off St. Thomas (Table S1), these stages are described in more detail below.

What appeared to be gamont stages of a haemogregarine were observed intraerythrocytically in 2 $P$. arcuatus, measuring $13.7 \pm 0.8(13.1-14.3) \times 2.5 \pm$ $0.1(2.5-2.6) \mu \mathrm{m}(\mathrm{n}=2)$ when lying circumnucleur one on either side of the host cell nucleus (Fig. 11), and approximately $17.6 \times 2.4 \mu \mathrm{m}(\mathrm{n}=1)$ when lying closely adjacent on one side of the host cell nucleus (Fig. 1m). The haemogregarine gamont cytoplasm stained a pale blue (Fig. 1l) or purple, respectively (Fig. 1m), with a pink loosely granulated nucleus. Furthermore, a gamont stage of a haemogregarine, similar in morphological appearance but much smaller than the above, was detected in what appeared to be a dehaemoglobinised erythrocyte from an individual L. bicaudalis (Fig. 1n). Unfortunately, no further examples were discovered.

Possible trophozoite stages of a haemogregarine were observed in the erythrocytes of a single $N$. usta usta, in both cases a double infection was observed (Fig. 1o). The stages measured $3.6 \pm 0.6(3-4.2) \times$ $1.9 \pm 0.2(1.6-2.1) \mu \mathrm{m}$, the cytoplasm staining whitish with loose pink chromatin material. On a single occasion, small possible trophozoite stages were seen parasitising a leucocyte from $S$. viride (Fig. 1p).

\section{Haemogregarina bigemina-like infections}

Four stages of a haemogregarine were detected in the mature erythrocytes of a L. gobio from St. Thomas, including a trophozoite stage, early meront and dividing meront stages, as well as paired gamont stages. Intensity of infection was calculated at $2 \%$ of the erythrocytes infected. Furthermore, extracellular gamonts were observed in the squash preparations of the gnathiids.
Rarely were trophozoite stages detected, measuring $3.1 \times 1.7 \mu \mathrm{m}(\mathrm{n}=1)$ (Fig. 2a), the nuclear chromatin arranged loosely as compared to that of the late meront, pregamont and gamont stages. Early meronts (Fig. 2b) and dividing meronts (Fig. 2c-f) were abundant, measuring $4.9 \pm 1(3.3-5.8) \times 2.9 \pm$ $0.8(1.9-4.5) \mu \mathrm{m}(\mathrm{n}=10)$, the nuclear chromatin of these later stages difficult to distinguish, particularly as they neared division (Fig. 2e,f). Early stage meronts were oval (Fig. 2b), whilst later stage meronts were round in shape (Fig. 2c-f). This appeared to be the case just prior to the onset of transverse binary fission (Fig. 2d,e), which resulted in 2 round meronts with tightly packed chromatin (Fig. 2e,f). Besides these round meront forms, elongate meronts were observed (Fig. 2g-k), these forms enclosing 2 merozoites or pregamonts, some at the onset of longitudinal binary fission (Fig. 2i-k), these most likely resulting in the paired slender gamonts often observed in erythrocytes (Fig. 2l,m). Gamonts measured 7.9 \pm 1.3 $(6.9-10.6) \times 1.6 \pm 0.6(1-2.8) \mu \mathrm{m}(\mathrm{n}=10)$, showing broad anterior ends with tapering, recurved posterior ends; the nucleus longer than wide and measuring $3 \pm 0.5(2.4-3.5) \times 1.8 \pm 0.1(1.4-2) \mu \mathrm{m}(\mathrm{n}=5)$, situated approximately midway along the gamont body. On a single occasion, what appeared to be extracellular gamonts were observed (Fig. 2n). Very rarely were intraleucocytic stages, identified at present as pregamonts, seen in lymphocytes (Fig. 2o,p).

\section{Babesiosoma-like infections}

Parasites resembling Babesiosoma species were observed in 2 fish species, an individual of Acanthurus bahianus (Acanthuridae) and a single $S$. adustus (Pomacentridae) from Saba and St. Thomas, respectively. Those found infecting $A$. bahianus resembled

Fig. 1. Giemsa stained light micrographs of blood parasites observed in the peripheral blood of fishes collected in the eastern Caribbean. (a-e) Stages of a Haemohormidium-like parasite in Stegastes adustus; a: possible early to b: late stage trophozoites; c,d: slender dividing stages with 3 adjacent strip-like nuclei; e: dividing stages which have separated into 3 possible 'gamont' or 'merozoite' stages. (f,g) A Haemohormidium-like parasite in an individual of Selar crumenophthalmus; f: sometimes bean shaped or $\mathbf{g}$ : round. (h,i) An additional Haemohormidium-like species observed in 1 individual each of Mugil curema and Stegastes adustus, respectively. (j) A viral-like organism detected in the nucleus of the infected erythrocyte of 2 Haemulon flavolineatum. (k) Haemogregarina bigemina-like haemogregarine, possible meront stage, in Hypleurochilus bermudensis. $(\mathbf{l}, \mathbf{m})$ Possible gamont stages of a haemogregarine observed intraerythrocytically in 2 Pomacanthus arcuatus; $\mathbf{l}$ lying circumnucleur, one on either side of the host cell nucleus, or $\mathbf{m}$ : lying closely adjacent on one side of the host cell nucleus. (n) A possible gamont stage of a haemogregarine in what appears to be a dehaemoglobinised erythrocyte, observed in a single Lactophrys bicaudalis. (o) Possible trophozoite stages of a haemogregarine in the erythrocytes observed in a single Nicholsina usta usta. (p) Rare, possible trophozoite stages parasitising a leucocyte observed in a single Sparisoma viride. (q,r) Parasites resembling Babesiosoma spp. observed in 2 fish species; q: very young trophozoite stages observed in a single Acanthurus bahianus and r: late trophozoite or young meront stages observed in a single S. adustus. (s,t) A parasite of unknown identity, observed to be encapsulated with an affinity for thrombocytes, found in several Ocyurus chrysurus. Scale bar $=10 \mu \mathrm{m}$ 

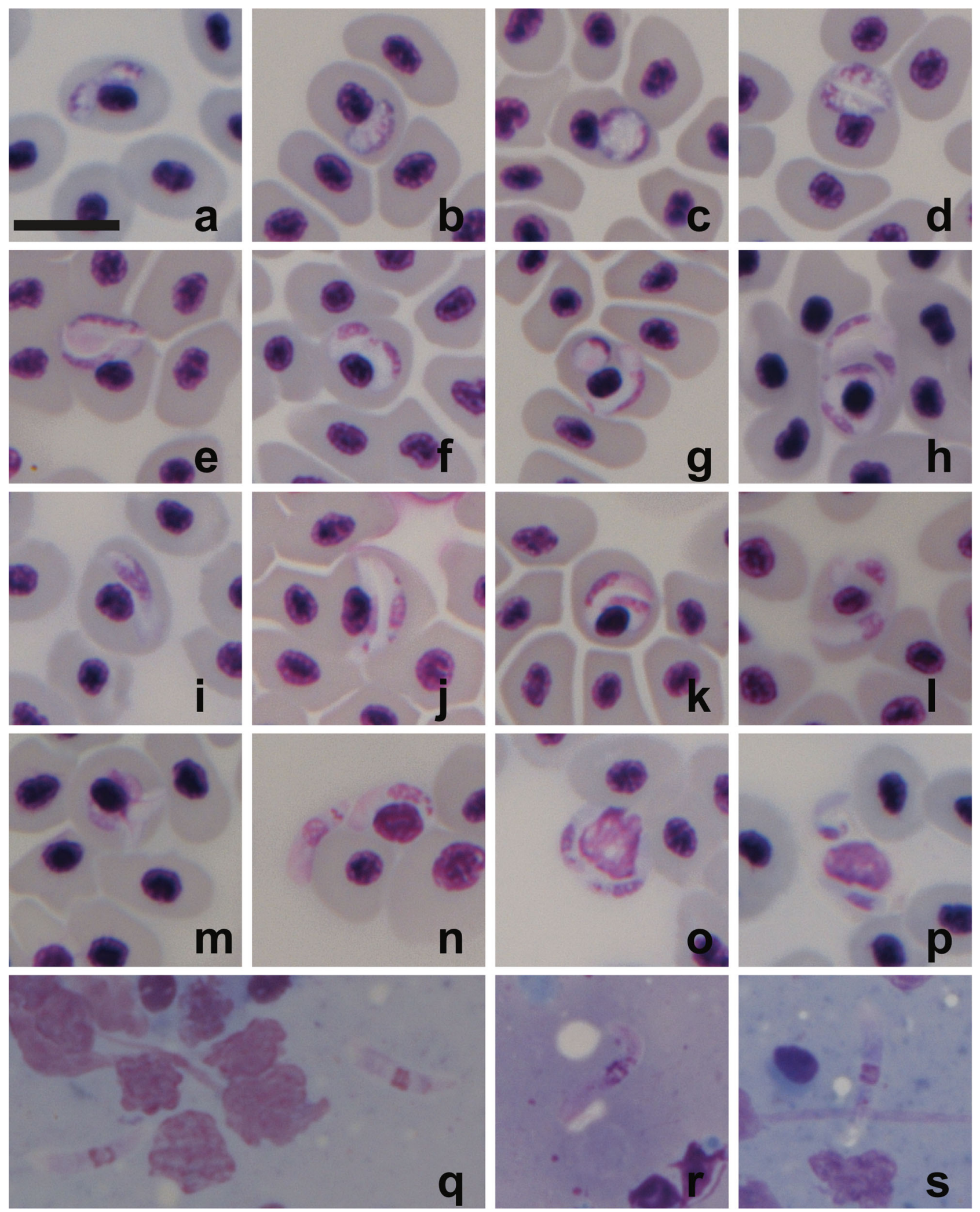
very young trophozoite stages, whilst those found infecting the $S$. adustus resembled late trophozoite or young meront stages (Fig. 1q,r). The latter stages were fairly large at $4.1 \pm 0.5(3.6-4.7) \times 2.8 \pm 0.4$ (2.5-3.3) $\mu \mathrm{m}(\mathrm{n}=4)$.

\section{Thrombocytic infection}

A parasite of unknown identity, observed to be encapsulated with an affinity for thrombocytes, and demonstrating a high parasitaemia infection $(80 \%$ or more), was detected in $86 \%$ of the Ocyurus chrysurus (Lutjanidae) from Culebra (Table S1 in the Supplement). This parasite was uniform in appearance, measuring $3.8 \pm 0.2(3.6-4.1) \times 2.2 \pm 0.1(2.1-2.4) \mu \mathrm{m}$ $(\mathrm{n}=5)$, the cytoplasm staining a pale blue from what was visible through the capsule, with a pink staining square nucleus measuring $1.1 \pm 0.2(0.9-1.4) \times 1.2 \pm$ $0.1(1.1-1.4) \mu \mathrm{m}(\mathrm{n}=5)$ (Fig. 1s,t).

\section{Infections from experiments with gnathiid larvae}

Gnathiid isopods, identified as G. marleyi (see Farquharson et al. 2012), were collected after a blood meal on redlip blenny (O. macclurei) and palehead blenny (L. gobio) infected with $H$. bigemina; dusky damselfish ( $S$. adustus) and threespot damselfish (S. planifrons) with Haemohormidiumlike infections, and French grunts (H. flavolineatum) with no history of any blood infections. Squashes of gnathiids that had fed on the French grunts and the 2 damselfish species did not reveal any stages of blood parasites. However, those of gnathiids that fed on $H$. bigemina infected fish harboured free gamont stages, measuring $12.1 \pm 1.6$ (10.6-14.5) $\times$ $1.9 \pm 0.2(1.5-2) \mu \mathrm{m}(\mathrm{n}=5)$, cytoplasm staining a light pink, nucleus measuring $2.2 \pm 0.6(1.7-3.2) \times$ $1.4 \pm 0.2(1.2-1.7) \mu \mathrm{m}(\mathrm{n}=5)$, situated approximately midway along the gamont body, staining pink, with either loose or densely packed chromatin, as seen in Fig. 2q-s. No further developmental stages were observed.

\section{DISCUSSION}

In previous surveys documenting the blood parasite biodiversity of reef fishes, including those carried out by Saunders $(1955,1958 a, b, 1959 a, b, 1964,1966)$ in the Caribbean, and subsequent studies on the GBR, Australia, haemogregarines were either the only, or the most prevalent, blood parasites reported (Smit et al. 2006). In contrast, in the present study haemogregarines were one of the least common of the parasite groups discovered.

Saunders (1954, 1955, 1958a,b, 1959a,b, 1966) only ever named 1 trypanosome and 3 haemogregarines infecting the fishes of the Caribbean region. The fourth and most commonly reported haemogregarine of Caribbean fishes by Saunders was $H$. bigemina, Saunders $(1955,1958 a, b, 1959 a, 1966)$ reporting this parasite from 21 families of fishes from this region with 17 of these families being reef-associated (see Davies et al. 2004). Eleven of the 17 families and 20 fish species sampled by Saunders were also sampled in our current study. None of these fish species, however, were found to be infected with $H$. bigemina in the present study. In fact, only 2 species, both blennoids: O. macclurei (Blenniidae) and L. gobio (Labrisomidae), were found to harbour a parasite similar to $H$. bigemina in the present study, neither of which was collected and examined by Saunders during her surveys. Saunders did, however, examine other species from both the Blenniidae and Labrisomidae families, but found them to be negative for $H$. bigemina and any of the other described haemogregarine species (see Saunders 1959a, 1966).

Species of fish, found to be infected with $H$. bigemina by Saunders and common to both Saunders' surveys and our own survey, were found in our study to be infected with entirely different parasites than H. bigemina. Ocyurus chrysurus (Lutjanidae), found during 3 surveys by Saunders $(1958 a, b, 1966)$ to harbour $H$. bigemina, was found in our study to be infected with a prevalent high parasitaemia infection of an unidentified encapsulated haemogregarinelike organism. Saunders never reported finding such an organism and never described anything similar

Fig. 2. Giemsa stained micrographs of stages of a haemogregarine resembling Haemogregarina bigemina (a-p) detected in the mature erythrocytes and lymphocytes observed in a single Labrisomas gobio, as well as (q-s) extracellular gamonts observed in ectoparasitic larvae of gnathiid isopods; a: a double trophozoite stage infection; b: an early stage oval meront and $\mathbf{c - g}$ : round dividing meronts; d: the nuclear chromatin of these later stages difficult to distinguish, particularly as they neared division; g-k: elongate meronts, i-k: enclosing 2 merozoites or pregamonts at the onset of longitudinal binary fission, $\mathbf{1}$,m: resulting in the paired slender gamonts often observed in erythrocytes; $\mathbf{n}$ : extremely rare extracellular gamonts; $\mathbf{o}$,p: even rarer intraleucocytic pregamonts; j-k: free gamont stages in Gnathia marleyi squashes made immediately post-feeding on the infected L. gobio. Scale bar $=10 \mu \mathrm{m}$ 
to it. Balistes capriscus (Balistidae), H. flavolineatum, H. plumieri (Haemulidae), Halichoeres bivittatus (Labridae) and Epinephelus guttatus (Serranidae) (Table S1 in the Supplement), were all found by Saunders (see Davies et al. 2004) to host H. bigemina, and $B$. capriscus to also host a trypanosome (Saunders 1959b). However, only viral infections were found in these species during the present study. The finding of high levels of infection in the snapper Ocyurus chrysurus has potentially important implications for Caribbean fisheries, as this species is arguably the most commonly exploited.

Those fish species found negative for any bloodparasitic infections or not examined during Saunders' $(1954,1955,1958 a, b, 1959 a, 1964,1966)$ surveys, with the exception of $O$. macclueri and L. gobio above, but positive during this study, included Acanthurus bahianus (Acanthuridae), Selar crumenophthalmus (Carangidae), Labrisomas kalisherae, Malacoctenus macropus and $M$. triangulates (Labrisomidae), Mugil curema (Mugilidae), Lactophrys bicaudalis (Ostracidae), Pomacanthus arcuatus (Pomacanthidae), Stegastes diencaeus, S. adustus, S. leucostictus, S. partitus and S. planifrons (Pomacentridae), Scarus taeniopterus, Nicholsina usta usta and Sparisoma viridae (Scaridae) (Table S1 in the Supplement). Parasitic infections comprised Babesiosoma-like organisms, Haemohormidium-like organisms, as well as haemogregarines, mostly intraerythrocytic (one intraleucocytic) none of which could be identified due to the lack of further developmental stages.

The combined observations of Saunders reported $H$. bigemina from a total of 28 families of fishes (see Davies et al. 2004). However, Davies et al. (2004) expressed their concern over such numerous sightings, particularly since Saunders never reported the complete development of $H$. bigemina during any of her studies, and furthermore did not report observation of the identifying paired mature gamonts characteristic of $H$. bigemina. Most of Saunders' observations of this parasite were identified from intraleucocytic forms or immature stages in erythrocytes (see Saunders 1955, 1958a,b, 1964, 1966, Davies et al. 2004) using inferior microscope equipment, and no photographs or voucher specimens were provided. The only other parasite, besides $H$. bigemina, observed to undergo what appears to be binary fission in the present study was the Haemohormidium-like parasite found to be most prevalent in the Pomacentridae (see Table S1). When first observed, it was thought plausible that Saunders may have been describing the same or a similar parasite, under the impression that it was $H$. bigemina based mostly on the binary fission, however, this was recognised not to be the case since most of her reports described a parasite similar in size to $H$. bigemina and thus far too large to be the Haemohormidium-like parasite reported here. Furthermore, the latter parasite was never seen parasitising leucocytes as was the case with Saunders' $H$. bigemina reports.

In this study, we sought not only to include species sampled by Saunders in the Caribbean, but also those that belonged to the same family as species known to harbour blood parasites at sites on the GBR, based on the more recent surveys of Smit et al. (2006) and Curtis et al. (2013). This comprised members of the families Acanthuridae, Balistidae, Carangidae, Chaetodontidae, Haemulidae, Labridae, Lutjanidae, Mullidae, Ostraciidae, Pomacentridae, Scaridae, Serranidae, and Tetraodontidae (Table S1 in the Supplement). Based on often high-levels of infection by haemogregarine and/or Haemohormidium-like haematozoa in Tetraodontids, Balistids, and Acanthurids from the Great Barrier Reef, we expected similar results for these families at our Caribbean sites. However, this was not the case. Aside from an apparent Babesiosoma and viral infection from a single Acanthurus bahianus, and a viral infection from a single Balistes capricus, we found no haematozoans in any members of these families.

Although not found in previous studies in the Caribbean and not sampled in recent Indo-Pacific studies, the finding of apparent haemogregarines in both families of Caribbean blennoid fishes is not surprising, considering their widespread occurrence in blennoids elsewhere (see Davies et al. 2004). What was surprising was the high prevalence of Haemohormidium-like blood parasites in Stegastes damselfishes. Among the 39 damselfishes (from 7 species) sampled by Smit et al. (2006), none were infected by blood parasites. Similarly, Saunders reported only a single Abudefduf infected with apparent $H$. bigemina, among 66 sampled, and no infections among 78 Stegastes or among 16 individuals from other damselfish genera. Infections in herbivorous damselfishes could have significant ecological consequences. Pomacentrids account for a large proportion of fish biomass on coral reefs and are a major food source for carnivorous species (e.g. Booth \& Beretta 2004), which includes many important to Caribbean fisheries. Territorial herbivorous species like most Stegastes are also key components of 'grazer' foraging guilds that play a major role in the structure and health of coral reef communities (e.g. Robertson 1984, Hixon \& Brostoff 1996). Thus, identifying the effect of these blood parasites on hosts, and their mode of transmission, should be a high priority. 
Our study focused on native reef-associated fishes of the Caribbean region. However, we opportunistically captured and collected blood samples from invasive Indo-Pacific lionfish at our sites. Although a protozoan blood parasite has been reported from lionfish in the northern part of its invaded range (Anderson et al. 2010), we found no evidence of blood parasites in the 16 lionfish we sampled, suggesting this blood parasite is uncommon and/or has a limited geographic range.

Our initial efforts to identify vectors of eastern Caribbean haematozoans focused on blennoid and damselfish as hosts, and gnathiid isopods as potential vectors. While our results for blennoids were largely consistent with other studies suggesting gnathiid isopods as vectors of haemogregarines in coral reef fishes, we did not find similar evidence for the haemohormidium-like parasite in Stegastes damselfishes. Given the high prevalence of blood parasites in both blennoids and Stegastes in our study, we expect the vector to be common. While leeches have been implicated in the transmission of some apicomplexan blood parasites, (Smit et al. 2006, Curtis et al. 2013) and have been reported on Stegastes in the Caribbean (Williams et al. 1994), they are not commonly observed, and they are rare at our study sites. Indeed, among the 316 damselfish and blennoids sampled during our study, we found only a single leech on a redlip blenny. In contrast, gnathiid isopods are abundant at our study sites (Sikkel et al. 2006, 2009b, Coile \& Sikkel 2013) and thus would appear to be the most likely vector. Ultimately, transmission experiments using candidate vectors and naïve hosts will be required to confirm the identity of the vectors.

With 103 species sampled, we present the most comprehensive survey of blood parasites of coral reef fishes to date. Parasites which were found during this study, but never reported infecting fishes of the Caribbean region by Saunders ranged, as can be seen above, from viral infections to Babesiosoma-like organisms, the latter to our knowledge being the only currently recorded possible Babesiosoma from marine fishes. It is quite apparent from the current survey that coral reefs do host a high biodiversity of fish blood parasites. Confirming their identity and phylogenetic relationships, their distribution among hosts and localities, mode of transmission, effects at the individual, population, and community level, as well as the environmental factors that promote their spread are obvious challenges for future work. In the future, elucidation of the mode of transmission and understanding the distribution of these parasites among hosts may be determined by close study of the different hosts' ecology. Blood parasite infections were limited primarily to species that are most active during the day (versus nocturnal or crepuscular). For now, however, no other obvious associations can be seen between host ecology and infection. Molecular tools exist for identification of many marine organisms, including coral reef macroparasites (e.g. Perkins et al. 2009). However, except for trypanosomes (Hayes et al. 2014), such tools remain in developmental stages for marine fish blood parasites, where the parasite DNA is so heavily 'diluted' by host DNA and where phylogenetic affiliations are so poorly known.

Parasites constitute an integral yet under-appreciated part of ecological communities (e.g. Combes 1996, Dobson et al. 2008, Netherlands et al. 2015), and their presence and abundance may influence and reflect a variety of ecosystem processes (Marcogliese 2005, Hudson et al. 2006). This will assist us when we assess the impact of anthropogenic activities on these processes. Recognizing that parasites dominate marine biodiversity and that fewer than $5 \%$ of papers in marine ecology journals focus on parasites (Poulin et al. 2014), we hereby hope to recruit more marine reef ecologists to contribute to these efforts.

Acknowledgements. We are grateful to the many people who assisted with the collection of fish and processing of blood samples. These include J. Artim, J. Barry, E. Brill, A. Coile, R. Ditter, N. Garvey, N. Gomez, P. Gomez, H. Gratil, W. Jenkins, A. McCammon, J. McCammon, L. Renoux, J. Sellers, W. Taylor, R. Welicky and R. Vante. We are also grateful to the following for providing facilities and logistic support: T. Boenevitas and St. Maarten Nature Conservancy; L. Castenaro and K. Wulf of Sea and Learn and Saba Marine Park; L. Jaerecki and the staff of Guana Island, Virgin Islands Environmental Resource Station (VIERS), St. John; P. Jobsis and the University of the Virgin Islands Center for Marine and Environmental Studies, St. Thomas; and M. Lucking and CORALations Culebra. We are especially grateful to the US National Science Foundation (OCE121615 , to P.C.S. as PI) for funding. Additional funding was provided by the Falconwood Corporation. We thank 3 anonymous reviewers for their constructive comments on the original manuscript. This paper is dedicated to the memory of Professor Angela Davies, cherished colleague and friend, whose expert knowledge, dedication and enthusiasm will be deeply missed. It is contribution number 137 from the University of the Virgin Islands Center for Marine and Environmental Studies.

\section{LITERATURE CITED}

Adlard RD, Miller TL, Smit NJ (2015) The butterfly effect: parasite diversity, environment, and emerging disease in aquatic wildlife. Trends Parasitol 31:160-166

Anderson ET, Stoskopf MK, Morris JA Jr, Clarke EO, Harms CA (2010) Hematology, plasma biochemistry and tissue 
enzyme activities of invasive red lionfish captured off North Carolina, USA. J Aquat Anim Health 22:266-273

Arias-González JE, Morand S (2006) Trophic functioning with parasites: a new insight for ecosystem analysis. Mar Ecol Prog Ser 320:43-53

Booth DJ, Beretta GA (2004) Influence of recruit condition on food competition and predation risk in a coral reef fish. Oecologia 140:289-294

Burreson EM (1989) Haematozoa of fishes from Heron Island, Australia, with a description of two new species of Trypanosoma. Aust J Zool 37:15-23

Coile AM, Sikkel PC (2013) Susceptibility of common Caribbean reef fishes to generalist ectoparasitc gnathiid isopods. Parasitology 140:888-896

Combes C (1996) Parasites, biodiversity and ecosystem stability. Biodivers Conserv 5:953-962

Cook CA, Smit NJ, Davies AJ (2009) A redescription of Haemogregarina fitzsimonsi Dias, 1953 and some comments on Haemogregarina parvula Dias, 1953 (Adeleorina: Haemogregarinidae) from southern African tortoises (Cryptodira: Testudinidae), with new host data and distribution records. Folia Parasitol 56:173-179

> Curtis LM, Grutter AS, Smit NJ, Davies AJ (2013) Gnathia aureamaculosa, a likely definitive host of Haemogregarina balistapi and potential vector for Haemogregarina bigemina between fishes of the Great Barrier Reef, Australia. Int J Parasitol 43:361-370

Das S, Lyla PS, Khan SA (2006) Marine microbial diversity and ecology: importance and future perspectives. Curr Sci 90:1325-1335

> Davies AJ (1982) Further studies on Haemogregarina bigemina Laveran and Mesnil, the marine fish Blennius pholis L., and the isopod Gnathia maxillaris Montagu. J Protozool 29:576-583

Davies AJ (1995) The biology of fish haemogregarines. Adv Parasitol 36:118-203

> Davies AJ, Johnston MRL (1976) The biology of Haemogregarina bigemina Laveran and Mesnil, a parasite of the marine fish Blennius pholis Linnaeus. J Protozool 23: 315-320

> Davies AJ, Johnston MRL (2000) The biology of some intraerythrocytic parasites of fishes, amphibians and reptiles. Adv Parasitol 45:1-107

Davies AJ, Smit NJ (2001) The life cycle of Haemogregarina bigemina (Adeleina; Haemogregarinidae) in South African hosts. Folia Parasitol 48:169-177

> Davies AJ, Eiras JC, Austin RTE (1994) Investigations into the transmission of Haemogregarina bigemina Laveran and Mesnil, 1901 (Apicomplexa: Adeleorina) between intertidal fishes in Portugal. J Fish Dis 17:283-289

> Davies AJ, Smit NJ, Hayes PM, Seddon AM, Wertheim DW (2004) Haemogregarina bigemina Laveran and Mesnil, 1901 (Protozoa: Apicomplexa: Adeleorina) —Past, present and future. Folia Parasitol 51:99-108

> Dobson A, Lafferty KD, Kuris AM, Hechinger RF, Jetz W (2008) Homage to Linnaeus: how many parasites? How many hosts? Proc Natl Acad Sci USA 105:11482-11489

> Dunne JA, Lafferty KD, Dobson AP, Hechinger RF and others (2013) Parasites affect food web structure primarily through increased diversity and complexity. PLoS Biol 11:e1001579

Farquharson C, Smit NJ, Sikkel PC (2012) Gnathia marleyi sp. nov. (Crustacea, Isopoda, Gnathiidae) from the Eastern Caribbean. Zootaxa 3381:47-61

Hatcher MJ, Dunn AM (2011) Parasites in ecological com- munities: from interactions to ecosystems. Cambridge University Press, Cambridge

Hayes PM, Smit NJ, Seddon AM, Wertheim DF, Davies AJ (2006) A new fish haemogregarine from South Africa and its suspected dual transmission with trypanosomes by a marine leech. Folia Parasitol 53:241-248

Hayes PM, Lawton SP, Smit NJ, Gibson WC, Davies AJ (2014) Morphological and molecular characterization of a marine fish trypanosome from South Africa, including its development in a leech vector. Parasit Vectors 7:50

Hixon MA, Brostoff WN (1996) Succession and herbivory: effects of differential fish grazing on Hawaiian coral-reef algae. Ecol Monogr 66:67-90

Hudson PJ, Dobson AP, Lafferty KD (2006) Is a healthy ecosystem one that is rich in parasites? Trends Ecol Evol 21: 381-385

> Huxham M, Raffaelli D, Pike A (1995) Parasites and foodweb patterns. J Anim Ecol 64:168-176

Kuris AM, Hechinger RF, Shaw JC, Whitney K and others (2008) Ecosystem energetic implications of parasite and free-living biomass in three estuaries. Nature 454: $515-518$

Lafferty KD, Dobson AP, Kuris AM (2006) Parasites dominate food web links. Proc Natl Acad Sci USA 103:11211-11216

Laird M (1951) A contribution to the study of Fijian haematozoa with descriptions of a new species from each of the genera Haemogregarina and Microfilaria. Publication no. 10, Department of Zoology, Victoria University College, Wellington. http://nzetc.victoria.ac.nz/tm/scholarly/ tei-Vic10Zool.html

Marcogliese DJ (2005) Parasites of the superorganism: Are they indicators of ecosystem Health? Int J Parasitol 35: $705-716$

Mouritsen KN, Poulin R (2005) Parasites boost biodiversity and change animal community structure by trait-mediated indirect effects. Oikos 108:344-350

Netherlands EC, Cook CA, Kruger DJ, Du Preez LH, Smit NJ (2015) Biodiversity of frog haemoparasites from subtropical northern KwaZulu-Natal, South Africa. Int J Parasitol Parasit Wildl 4:135-141

Perkins EM, Donnellan SC, Bertozzi T, Chisolm LA, Whittington ID (2009) Looks can deceive: molecular phylogeny of a family of flatworm ectoparasites (Monogenea: Capsalidae) does not reflect current morphological classification. Mol Phylogenet Evol 52:705-714

Poulin R, Blasco-Costa I, Randhawa HS (2014) Integrating parasitology and marine ecology: seven challenges towards greater synergy. J Sea Res, doi:10.1016/j.seares. 2014.10.019

$>$ Robertson DR (1984) Cohabitation of competing territorial damselfishes on a Caribbean coral reef. Ecology 65: 1121-1135

> Rohde K (2002) Ecology and biogeography of marine parasites. Adv Mar Biol 43:1-86

> Saunders DC (1954) A new haemogregarine reported from the spotted squeteague, Cynoscion nebulosus, in Florida. J Parasitol 40:699-700

Saunders DC (1955) The occurrence of Haemogregarina bigemina Laveran and Mesnil and $H$. achiri n. sp. in marine fish from Florida. J Parasitol 41:171-176

> Saunders DC (1958a) The occurrence of Haemogregarina bigemina Laveran and Mesnil, and $H$. dasyatis n. sp. in marine fish from Bimini, Bahamas, B.W.I. Trans Am Microsc Soc 77:404-412

Saunders DC (1958b) Blood parasites of the marine fishes of 
the Florida Keys. Year Book Am Philos Soc 1958:261-266

Saunders DC (1959a) Haemogregarina bigemina Laveran and Mesnil from marine fishes of Bermuda. Trans Am Microsc Soc 78:374-379

Saunders DC (1959b) Trypanosoma balistes n. sp. from Balistes capriscus Gmelin, the common triggerfish, from the Florida Keys. J Parasitol 45:623-626

Saunders DC (1960) A survey of the blood parasites in the fishes of the Red Sea. Trans Am Microsc Soc 79:239-252

Saunders DC (1964) Blood parasites of marine fish of southwest Florida, including a new Haemogregarine from the Menhaden, Brevoortia tyrannus (Latrobe). Trans Am Microsc Soc 83:218-225

Saunders DC (1966) A survey of the blood parasites of the marine fishes of Puerto Rico. Trans Am Microsc Soc 85: 193-199

Siddall ME (1995) Phylogeny of adeleid blood parasites with a partial systematic revision of the haemogregarine complex. J Eukaryot Microbiol 42:116-125

Sikkel PC, Schaumburg CS, Mathenia JK (2006) Diel infestation dynamics of gnathiid isopod larvae parasitic on Caribbean reef fish. Coral Reefs 25:683-689

Sikkel PC, Nemeth D, McCammon A, Williams JEH (2009a) Habitat and species differences in prevalence and intensity of Neobenedenia melleni (Monogenea: Capsalidae) on sympatric Caribbean surgeonfishes (Acanthuridae). J Parasitol 95:63-68

Sikkel PC, Ziemba RE, Sears W, Wheeler J (2009b) Ontogenetic shifts in timing of host infestation by parasitic

Editorial responsibility: Ivan Nagelkerken,

Adelaide, South Australia, Australia gnathiid isopod larvae on Caribbean coral reefs. Coral Reefs 28:489-495

Smit NJ, Davies AJ (1999) New host records for Haemogregarina bigemina Laveran \& Mesnil, 1901 (Apicomplexa; Adeleina) from South Africa. J Mar Biol Assoc UK 79: 933-935

> Smit NJ, Davies AJ (2001) An encapsulated haemogregarine from the evileye pufferfish in South Africa. J Mar Biol Assoc UK 81:751-754

> Smit NJ, Grutter AS, Adlard RD, Davies AJ (2006) Hematozoa of teleosts from Lizard Island, Australia with some comments on their possible mode of transmission and the description of a new hemogregarine species. J Parasitol 92:778-788

Thomas F, Renaud F, de Meeûs T, Poulin R (1998) Manipulation of host behaviour by parasites: ecosystem engineering in the intertidal zone? Proc R Soc B 265: 1091-1096

Thompson RM, Mouritsen KN, Poulin R (2005) Importance of parasites and their life cycle characteristics in determining the structure of a large marine food web. J Anim Ecol 74:77-85

Williams EH Jr, Bunkley-Williams L, Burreson EM (1994) Some new records of marine and freshwater leeches from Caribbean, Southeastern USA, Eastern Pacific, and Okinawan animals. J Helminthol Soc Wash 61:133-138

> Wood CL, Byers JE, Cottingham KL, Altman I, Donahue MJ, Blakeslee AMH (2007) Parasites alter community structure. Proc Natl Acad Sci USA 104:9335-9339

Submitted: April 15, 2015; Accepted: July 18, 2015 Proofs received from author(s): July 31, 2015 